\title{
IMMOBILISATION OF LINEAR AND CYCLIC RGD-PEPTIDES ON TITANIUM SURFACES AND THEIR IMPACT ON ENDOTHELIAL CELL ADHESION AND PROLIFERATION
}

\author{
P.W. Kämmerer ${ }^{1 \S *}$, M. Heller ${ }^{1 \S}$, J. Brieger ${ }^{2}$, M.O. Klein ${ }^{1}$, B. Al-Nawas ${ }^{1}$ and M. Gabriel ${ }^{3}$ \\ ${ }^{1}$ Department of Oral and Maxillofacial Surgery, ${ }^{2}$ Department of Otorhinolaryngology, ${ }^{3}$ Department of Cardiothoracic \\ and Vascular Surgery, University Medical Centre of the Johannes Gutenberg-University Mainz, Mainz, Germany
}

${ }^{\S}$ These authors contributed equally to this study.

\begin{abstract}
Functional coatings on titanium vascular stents and endosseous dental implants could probably enhance endothelial cell (EC) adhesion and activity with a shortening of the wound healing time and an increase of peri-implant angiogenesis during early bone formation. Therefore, the role of the structure of linear and cyclic cell adhesive peptides Arg-Gly-Asp (1-RGD and c-RGD) on differently pre-treated titanium (Ti) surfaces (untreated, silanised vs. functionalised with 1- and c-RGD peptides) on EC cell coverage and proliferation was evaluated. After 24 $\mathrm{h}$ and after $3 \mathrm{~d}$, surface coverage of adherent cells was quantified and an alamarBlue ${ }^{\circledR}$ proliferation assay was conducted. After 24 h, 1-RGD modified surfaces showed a significantly better coverage of adhered cells than untreated titanium $(p=0.01)$. Differences between 1-RGD surfaces and silanised $\operatorname{Ti}(p=0.066)$ as well as between l-RGD and c-RGD surfaces $(p=0.191)$ were not significant. After $3 \mathrm{~d}$, $c-R G D$ surfaces showed a significantly higher cell coverage than untreated Ti, silanised and 1-RGD titanium surfaces (all $p<0.0001$ ). After $24 \mathrm{~h}, \mathrm{c}-\mathrm{RGD}$ modified surfaces showed significant higher cell proliferation compared to untreated $\operatorname{Ti}(p=0.003)$. However, there were no differences in proliferation between c-RGD and l-RGD $(p=0.126)$ or c-RGD and silanised titanium $(p=0.196)$. After $3 \mathrm{~d}$, proliferation on c-RGD surfaces outranged significantly untreated titanium $(p=0.004)$, silanised $(p=0.001)$ and 1-RGD surfaces ( $p=0.023$ ), whereas no significant difference could be found between untreated Ti and 1-RGD surfaces $(p=0.54)$. According to these results, the biomimetic coating of c-RGD peptides on conventional titanium surfaces showed a positive effect on EC cell coverage and proliferation. We were able to show that modifications of titanium surfaces with c-RGD are a promising approach in promoting endothelial cell growth.
\end{abstract}

Keywords: RGD modification, titanium, immobilisation, linear, cyclic, endothelial cells.

*Address for correspondence:

Peer W. Kämmerer

Department of Oral and Maxillofacial Surgery

University Medical Centre of the Johannes GutenbergUniversity Mainz,

Augustusplatz 2, D-55131 Mainz, Germany

Telephone Number: 004906131/17-5086

FAX Number: 06131/17-6602.

E-mail: peer.kaemmerer@unimedizin-mainz.de

\section{Introduction}

Stable and uneventful healing of endosseous implants and vascular stents is an essential precondition for long-term success of the implant. Implant surface characteristics have a direct influence on the functional integration into the surrounding tissue. In certain subpopulations, and depending on a particular material use, an increased implant and prosthesis failure can be seen (Davies and Hagen, 1993; Balaji, 2008; Huynh-Ba et al., 2008; Fine et al., 2009; Javed and Romanos, 2009; Linsen et al., 2009; Mellado-Valero et al., 2009). This underlines the importance of developing strategies to enhance endothelialisation (Fine et al., 2009) as well as periimplant new bone formation (Schliephake et al., 2005) with faster wound healing around the biomaterial to increase short- and long-term implant stability.

Accordingly, for vascular stents, the creation of a uniform healthy endothelium on the inner surface would be favourable in order to mask the underlying titanium material from inflammatory cell interference (Fine $e t$ al., 2009) and to play a regulatory role in haemostasis and thrombosis (Wu et al., 1988). It has been observed that conventional metal stents can trigger an inflammatory response which can even result in scar formation (James et al., 1990). This amplifies the possibility of ongoing obliteration, re-stenosis, especially in small diameter prostheses.

For dental titanium implants, survival length is determined by interactions between implant surface and hard and soft tissues. Especially in the early stages of wound healing these interactions play a determining role. Endothelial cells (ECs) are crucially involved in angiogenesis and, due to increased nutrition (Davies and Hagen, 1993), in further wound healing processes (An et al., 2009). As a conclusion, timely and sufficient angiogenesis at the dental implant surface is essential for a successful bone healing. Accordingly, an association between inadequate bone vascularity and decreased bone formation/ mass has been shown (Burkhardt et al., 1987; Glowacki, 1998). An inhibition of angiogenesis during fracture healing in rats in vitro resulted in formation of fibrous tissue only (Hausman et al., 2001). Furthermore, poor blood supply has been identified as a risk factor for the failure of osteogenesis (Huang et al., 2005; Kanczler and Oreffo, 2008) and functional osseointegration of dental endosseous implants (Carano and Filvaroff, 2003). In addition, a supplemental close and reciprocal interaction and stimulation between ECs and bone cells has been 

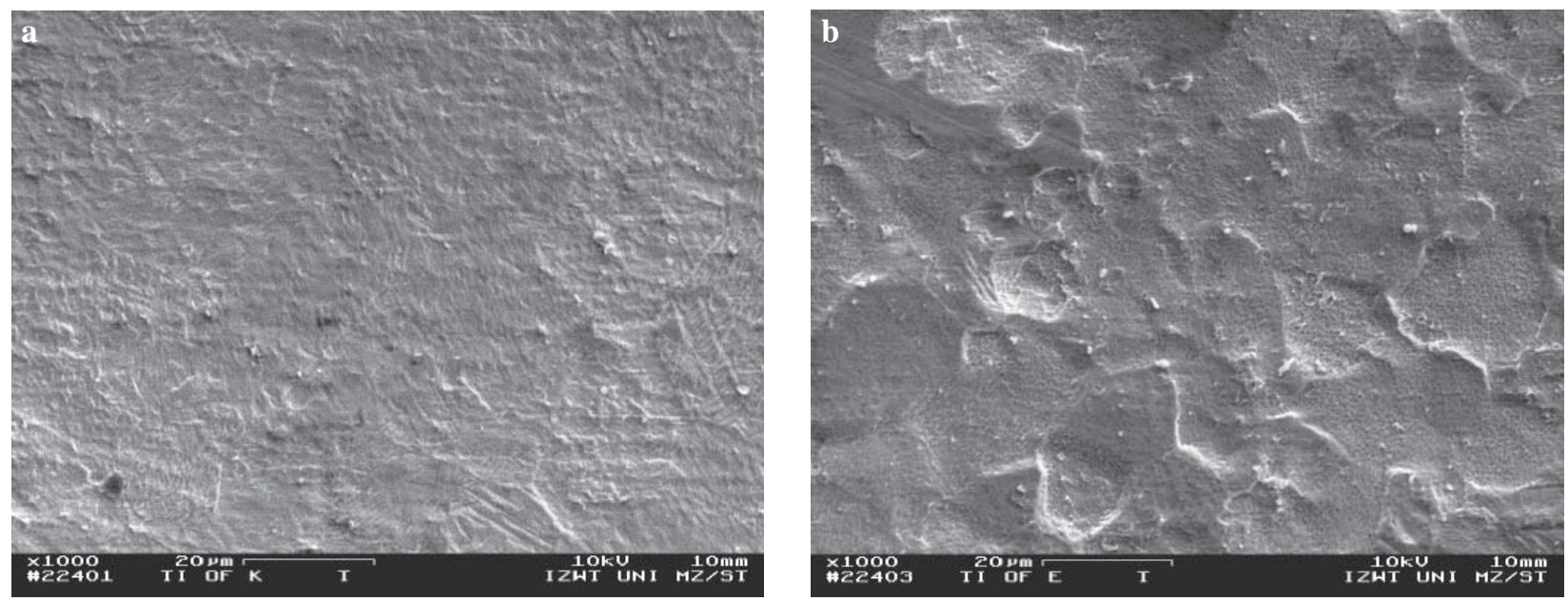

Fig. 1. (a) Scanning electron microscopy (SEM; DSM 962 scanning microscope, Carl Zeiss, Oberkochen, Germany) of the surface of a titanium disc (working distance: $10 \mathrm{~mm}$; accelerating voltage: $10 \mathrm{kV}$ ) after grinding (mean roughness ( $\left.\mathrm{R}_{\mathrm{a}}\right) 1.31 \mu \mathrm{m}$ ). (b) SEM of the surface of a titanium disc (working distance: $10 \mathrm{~mm}$; accelerating voltage: $10 \mathrm{kV}$ ) after grinding and 3 min of etching (mean roughness $\left.\left(\mathrm{R}_{\mathrm{a}}\right) 1.31 \mu \mathrm{m}\right)$.

described (Wang et al., 1997; Bouletreau et al., 2002; Carano and Filvaroff, 2003).

For the biomaterials described above, an increased activation of ECs on the surface with subsequent increased EC growth has been identified as a strategy to enhance implant healing (Choi et al., 2008; Kanczler and Oreffo, 2008; Fine et al., 2009). A promising approach to enhance endothelial cell affinity (Choi et al., 2008), as well as further peri-implant bone regeneration (Schliephake et al., 2002), is the use of certain peptides such as the threeamino acid motif Arg-Gly-Asp (RGD) that is a primary recognition site in extracellular matrix proteins (Kim et al., 2005). This motif can enhance cellular integrin-mediated cell adhesion to different surfaces and may thus help to increase the biocompatibility of the material (Bhadriraju and Hansen, 2000; Holland et al., 1998; Pallu et al., 2009; Schliephake et al., 2005). RGD-peptides have been shown to regulate cell adhesion of osteoprogenitor cells (Verrier et al., 2002) and osteoblasts on titanium surfaces (Secchi et al., 2007). An increased bone formation in vivo employing RGD-peptides on titanium surfaces has been reported (Ferris et al., 1999; Kroese-Deutman et al., 2005).

Activation of ECs by RGD motifs mediated by integrin receptors (Matsuura et al., 2000) has been reported in various studies (Lin et al., 1992; Lin et al., 2001; Massia and Stark, 2001) and has been examined for RGDcoatings on polymer surfaces (Hirano et al., 1993). To our knowledge, an examination of interactions between ECs and RGD-peptides on titanium surfaces has not been conducted to date.

Differences in the biological features of linear and cyclic RGD-peptides have been described earlier (Kim et al., 2005; Kostidis et al., 2004; Verrier et al., 2002; Xiao and Truskey, 1996). It has been observed that cyclic RGDpeptides influence platelet aggregation more efficiently than linear ones (Kim et al., 2005). After a short incubation time, bovine aortic endothelial cells have shown higher rates of adhesion on glass surfaces, functionalised with immobilised cyclic RGD peptide, than with linear RGD peptide (Xiao and Truskey, 1996). On the other hand, delivery of sphingosine 1-phosphate by linear RGD peptide showed an increased formation and better long-termadhesion of endothelial cells than with cyclic RGD peptide, though adhesion strengths were higher on cyclic RGD (Wacker et al., 2008). These results indicate the importance of sequence, structure and conformation of the peptide. Differences in cellular interactions with RGD peptides of different conformation and orientation of the amino acids (Verrier et al., 2002) require a better understanding. The specification of the most appropriate RDG-form for EC activation may have big impact on further modification development techniques. To our knowledge, this interesting question has also not been examined in prior studies either.

Therefore, the aim of this study was to determine the role of the structure of linear and cyclic RGD-containing peptides immobilised onto titanium surfaces for EC cell coverage and proliferation.

\section{Materials and Methods}

\section{Preparation of titanium discs}

A titanium sheet (Ti; 99.7\% alloy; Alfa Aesar, Karlsruhe, Germany) with a thickness of $2 \mathrm{~mm}$ was cut into $10 \times 10$ $\mathrm{mm}^{2}$ pieces. Grinding of the Ti-plates was accomplished in a series of steps using wet grinding paper $(400,800$ 1200 and 2000 grid). Samples were etched in a solution of $9 \% \mathrm{NH}_{4} \mathrm{FxHF}, 8.5 \%$ concentrated sulphuric acid and $0.5 \%$ urotropin in water for $3 \mathrm{~min}$ at room temperature. After rinsing with water, the specimens were oxidised in Piranha-solution $\left(30 \% \mathrm{H}_{2} \mathrm{O}_{2}, \mathrm{H}_{2} \mathrm{SO}_{4}\right.$ concentration (1:1)) for $1 \mathrm{~h}$ at room temperature followed by washing in water.

\section{Roughness measurements and scanning electron microscopy}

In order to show the influence of etching and oxidation on Ti surfaces, the roughness of samples was analysed by dynamical focusing (Marsurf XR 20, Mahr GmbG, 
Göttingen, Germany). Calculation was performed with the software Marsurf XR $20 \mathrm{~V}$ 1.21-1 (Mahr GmbG). Additionally, before and after etching and after oxidizing procedures, scanning electron microscopy (SEM; DSM 962 scanning microscope, Carl Zeiss, Oberkochen, Germany) of the surfaces was conducted to verify the results optically. An example of the results is shown in Fig. 1a,b. The roughness of these samples can be compared to machined or double etched titanium dental implant surfaces (AlNawas and Götz, 2003).

\section{Silanisation and RGD-immobilisation of Ti samples}

Silanisation of oxidised samples was performed in 5\% Aminopropyl-triethoxysilane (APTES; Sigma-Aldrich, Deisenhofen, Germany) in toluene at room temperature overnight. After cleaning in toluene and ethanol, samples were cured at $80{ }^{\circ} \mathrm{C}$ for $1 \mathrm{~h}$. Subsequently, aminosilanised Ti-plates were immersed in a $5 \%$ solution of diethyleneglycol diglycidylether (diepoxide) in $50 \mathrm{mM}$ carbonate-buffer ( $\mathrm{pH}$ 9) for $2 \mathrm{~h}$. The excess solution was removed by repeated rinsing with water. RGDimmobilisation was then immediately performed by incubating the activated samples in $0.5 \mathrm{mg} / \mathrm{mL}$ RGDpeptide (1-RGD: Sigma-Aldrich; c-RGD: Anaspec, Fremont, CA, USA, respectively) in carbonate-buffer overnight in a wet chamber. The samples were stored dry after being thoroughly rinsed with water. Although theoretically other methods of sterilisation would have been possible (Hersel et al., 2003) for the cell experiments, chemical sterilisation with $70 \%$ ethanol for $30 \mathrm{~min}$ has shown to be sufficient.

\section{Distribution and surface density of primary amino groups on Ti discs}

Amino-silanised Ti-samples were subjected to fluorescent labelling. Fluorescein isothiocyanate (FITC; $0.5 \mathrm{mg} / \mathrm{mL}$ ) dissolved in buffer was given to the APTES-modified Ti for $1 \mathrm{~h}$ and non-reacted dye was removed with ethanol. Micrographs were taken on an Olympus X-70 fluorescence microscope (Olympus, Hamburg, Germany; Fig. 2). Successful coating was analysed by means of the sulphoSDTB-assay (Interchim, Mannheim, Germany) according to the manufacturer's instructions.

\section{Static contact angle microscopy}

Before experimental use, the hydrophilic properties of untreated and RGD modified Ti samples were examined by static water contact angle microscopy (Krüss DSA 10-MK2; Krüss Optronic, Hamburg, Germany) in order to quantify the amount of RGD peptide (Hersel et al., 2003). Smaller contact angles (CA) indicate an increased hydrophilicity of a solid surface and are usually detected when the zwitterionic RGD moieties are immobilised (Lin et al., 1992; Lin et al., 1994). All measurements were done in triplicate. Mean values as well as standard deviations (SD) are given.

\section{Cell culture}

50,000 ECs (25,000/mL; Human Aortic Endothelial Cells, PromoCell, Heidelberg, Germany) from three donors (male $n=1$, female $n=2 ; 28-31$ years (mean: 29)) were cultivated separately in 24-well plates in Endothelial Cell Growth Medium (ECGM, PromoCell) including manufacturer's supplement. According to the manufacturer's information, ECGM with supplement $(0.004 \mathrm{~mL} / \mathrm{mL})$ contains $1 \mathrm{ng} / \mathrm{mL}$ basic Fibroblast Growth Factor, $0.004 \mathrm{~mL} / \mathrm{mL}$ Endothelial Cell Growth Factor, $0.1 \mathrm{ng} / \mathrm{mL}$ Epidermal Growth Factor, $22.5 \mu \mathrm{g} / \mathrm{mL}$ heparin, $1 \mu \mathrm{g} / \mathrm{mL}$ hydrocortisone, $0.62 \mathrm{ng} / \mathrm{mL}$ phenol red and $0.02 \mathrm{~mL} / \mathrm{mL}$ foetal bovine serum. Cells were cultured at $37{ }^{\circ} \mathrm{C}, 5 \% \mathrm{CO}_{2}$ and $95 \%$ rel. humidity. The medium was changed every two days. To detach the cells, Accutase/PBS (phosphate buffered saline) (PAA, Pasching, Austria) was used.

\section{Interactions between titanium discs and ECs}

Initial cell-substrate interactions were tested by incubating the untreated, APTES and RGD-modified Ti-specimen with $5 \times 10^{4}$ cells in $2 \mathrm{~mL}$ of medium per sample. Behaviour of cells (cell coverage, proliferation) was evaluated at fixed time points ( $24 \mathrm{~h}$ and $3 \mathrm{~d}$ after incubation).

\section{Cell coverage}

Cell coverage was quantified by microscopic measurement of covered surface. The total area the cells were plated onto was $10 \times 10 \mathrm{~mm}^{2}$. Cells can adhere differently on different areas of the examined surface. Therefore, a single photograph cannot reflect the ratio of cell distribution on the whole surface. To minimise this problem, examinations of the percentage of colonised surfaces were done in three randomly chosen areas for each group of donor cells. To visualise attached cells, the Ti-plates were rinsed with PBS and subsequently incubated in foetal calf serum (FCS)-free medium containing $1 \mu \mathrm{g} / \mathrm{mL}$ Calcein-acetoxymethylester. Calcein specifically stains vital cells. After $30 \mathrm{~min}$ of incubation at $37{ }^{\circ} \mathrm{C}$, samples were again washed with medium. Micrographs were obtained using standard fluorescein isothiocyanate (FITC) filters. Surface coverage of attached cells was quantified with ImageJ software (NIH, Bethesda, MD, USA) and expressed as percentage of total area.

\section{Proliferation}

Proliferation of cells was assayed with the alamarBlue ${ }^{\circledR}$ substrate (Invitrogen, Karlsruhe, Germany). For this purpose, Ti-plates were rinsed with PBS and immersed in $1 \mathrm{~mL}$ FCS-free medium containing $100 \mu \mathrm{L}$ alamarBlue ${ }^{\circledR}$ solution (concentration 10\%). Controls (pure medium without EC with alamarBlue ${ }^{\circledR}$ substrate) were processed in parallel. After $3 \mathrm{~h}$, relative fluorescence units, indicating cellular metabolism, corresponding to the cellular proliferative activity (Ahmed et al., 1994), were determined by the use of a Fluoroscan Ascent - reader (Thermo Scientific, Schwerte, Germany). Wavelengths were $538 \mathrm{~nm}$ for excitation and $600 \mathrm{~nm}$ for emission. Control values were subtracted; measurements were done in triplicate for each EC donor sample.

\section{Statistics}

A one-way analysis of variance (ANOVA) with Tukey simultaneous post-hoc test was conducted to compare groups. Altogether, the interactions of three commercial available EC samples from different donors with different 
surfaces were evaluated. Each sample was measured in triplicate. The nature of this experiment was exploratory; therefore, we report descriptive $p$-values of tests. $P$ values $<0.05$ were termed significant. The analyses were conducted using SPSS version 15.0 (SPSS, Chicago, IL, USA).

\section{Results}

\section{Distribution and surface density of primary amino- groups on Ti-discs}

The amount of accessible amino functions was determined using a colorimetric sulpho-SDTB assay (Fig. 2). The presented silanisation protocol generated a mean of 7 $\mathrm{NH}_{2}$-groups per $\mathrm{nm}^{2}$.

\section{Static water contact angle microscopy}

The untreated samples showed a mean contact angle (CA) of $90.8^{\circ}$ (Standard Deviation (SD) 3.1). After silanisation and coating with RGD peptides, a mean CA of $18.1^{\circ}$ (SD 4.5) was measured. Therefore, together with clinical observations, a successful immobilisation was assumed. No significant difference in water contact angle measurements could be seen between 1- and c-RGD surfaces.

\section{Surface coverage}

Surface coverage of ECs was evaluated on untreated and on modified (APTES, 1-RGD, c-RGD) titanium surfaces. On each surface, three randomly chosen different areas ( $3 \times 3)$ were examined. These data were used to generate mean values and to calculate the statistical tests.

After $24 \mathrm{~h}$, only marginal surface coverage was observed on untreated surfaces. On silanised surfaces as well as on both RGD-surfaces, EC adhesion was increased (Fig. 3). Accordingly, the untreated surface showed a mean colonisation of 7.1\% (SD 1.04), followed by APTES surface (13\%; SD 5.08), c-RGD (16.4\%; SD 3.35) and 1-RGD (26.1\%; SD 8.69; Fig. 4a).

A statistically significant difference was found between untreated and 1-RGD surfaces ( $p=0.01$ ). Between c-RGD surfaces and untreated titanium, the difference was not statistically significant $(p=0.223)$. Between APTES and RGD-modified surfaces, no significant difference was seen after $24 \mathrm{~h}$ (1-RGD: $p=0.066$; c-RGD: $p=0.868$ ). In addition, the difference between 1-RGD and c-RGD surfaces was not significant ( $p=0.191$; Fig. $4 \mathrm{a}$ ).

After 3 days, coverage of ECs was less on surfaces with 1-RGD-peptide, whereas the highest coverage of adhered cells was seen on c-RGD surfaces. The coverage of untreated and APTES surfaces ranged between the coverage values of 1- and c-RGD-peptide. Accordingly, the untreated surface exhibited increased cell coverage (9.1\%; SD $1.43 ;+2 \%)$, the APTES surface had a cell coverage of $4.6 \%$ (SD $0.36 ;-8.4 \%$ ), the c-RGD surface gained 3.9\% (20.3\%; SD 1.68), l-RGD surface lost 16\% of cell coverage (10.1\%; SD 0.17) (Fig. 5). The difference between untreated and APTES surfaces was seen to be statistically significant $(p=0.005)$ after $3 \mathrm{~d}$. Differences between APTES and RGD-modified surfaces were significant as well (1-RGD: $p=0.001$; c-RGD: $p<0.0001$ ).

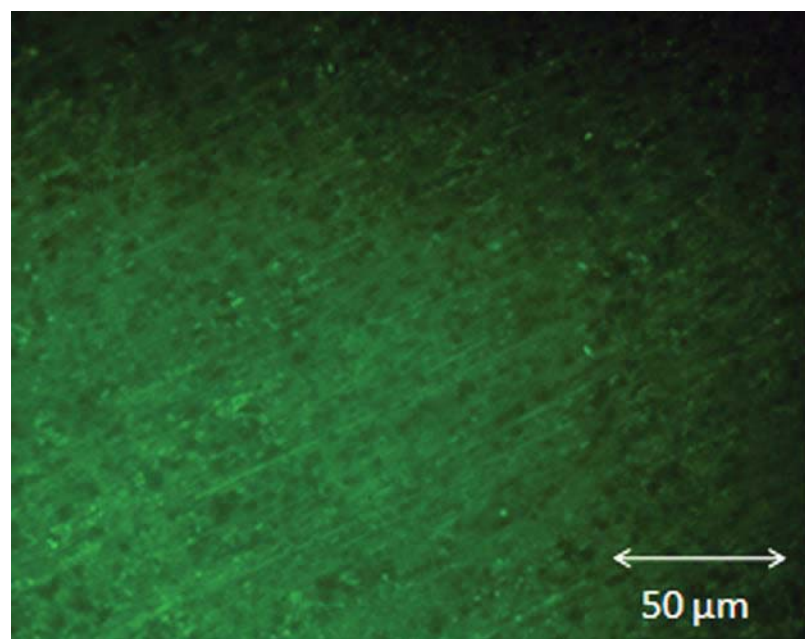

Fig. 2. FITC stain of titanium surface after silanisation with 5\% APTES in toluene. Amino groups are distributed equally.

Colonisation on c-RGD surfaces differed significantly from untreated titanium $(p=0.001)$, though no significant difference could be found between untreated and l-RGD surfaces $(p=0.722)$. The comparison between 1-RGD and c-RGD surfaces showed a significant difference in favour of c-RGD ( $p<0.0001$; Fig. 4b).

\section{Proliferation}

The proliferative activity of ECs was analyzed with the alamarBlue $^{\circledR}$ assay and measured as fluorescence units. Additionally, data are calculated as a percentage of controls (PC). After $24 \mathrm{~h}$, the lowest mean activity was observed in ECs cultured on untreated titanium (7.26 Fluorescence Units (FU); SD 1.05; PC 100\%), followed by APTES (24.58 FU; SD 5.29; PC 311\%) and 1-RGD surfaces (22.46 FU; SD 1.09; PC 279\%). The highest proliferative activity could be seen in cultures on c-RGD surfaces (36.56 FU; SD 11.99; PC 463\%; Fig. 6a). Accordingly, the difference between untreated and APTES surfaces was seen to be statistically significant $(p=0.049)$. As between untreated and RGD modified surfaces, the differences were significant for c-RGD only (1-RGD: $p=0.077$; c-RGD: $p=0.003)$. Neither between APTES and RGD modified (1-RGD: $p=0.988$; $c-R G D: p=0.196)$ nor between the two RGD modifications ( $p=0.126)$ were significant differences detected (Fig. 6).

After $3 \mathrm{~d}$ on APTES surfaces, a decrease of proliferative activity was observed (-3.48 FU) whereas an increase was seen on untreated (+40.12 FU) and RGD-modified surfaces (1-RGD +49.84; c-RGD +82.43). Altogether, after $3 \mathrm{~d}$ of incubation, minimum activity could be observed on APTES surfaces (21.1 FU; SD 4.83; PC 45\%), followed by untreated (47.41 FU; SD 4.71; PC 100\%), 1-RGD (72.3 FU; SD 21.5; PC 153\%) and c-RGD surfaces (119 FU; SD 23.6; PC 251\%; Fig. 6b). No significant difference between untreated and APTES surfaces $(p=0.305)$ was seen. After $3 \mathrm{~d}$, the difference in proliferation was significant between APTES and RGD modified surfaces (l-RGD: $p=0.045$; c-RGD: 0.001). Proliferation on c-RGD surfaces differed significant from untreated titanium $(p=0.004)$, though no 
Titanium, oxidised

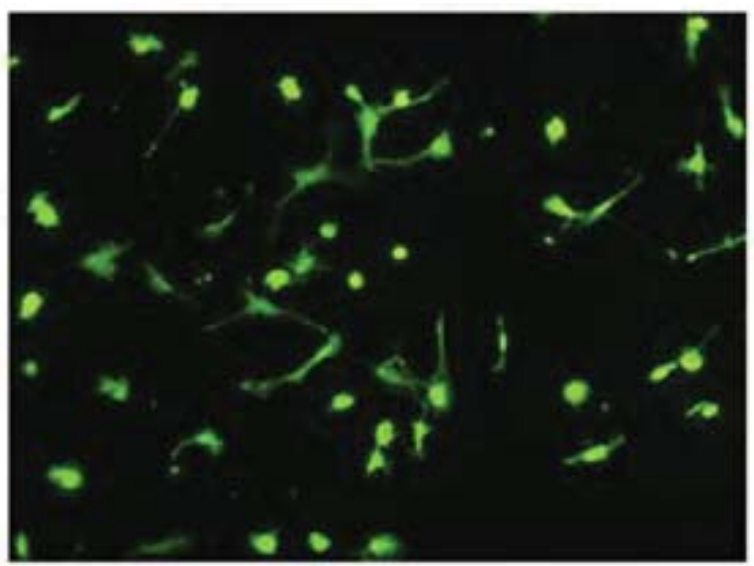

$200 \mu \mathrm{m}$

Titanium, 1-RGD

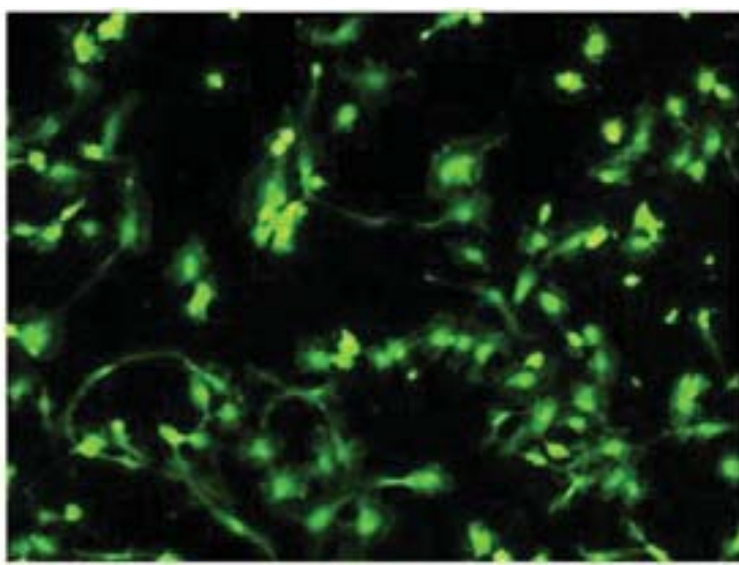

$200 \mu \mathrm{m}$
Titanium, silanised (APTES)

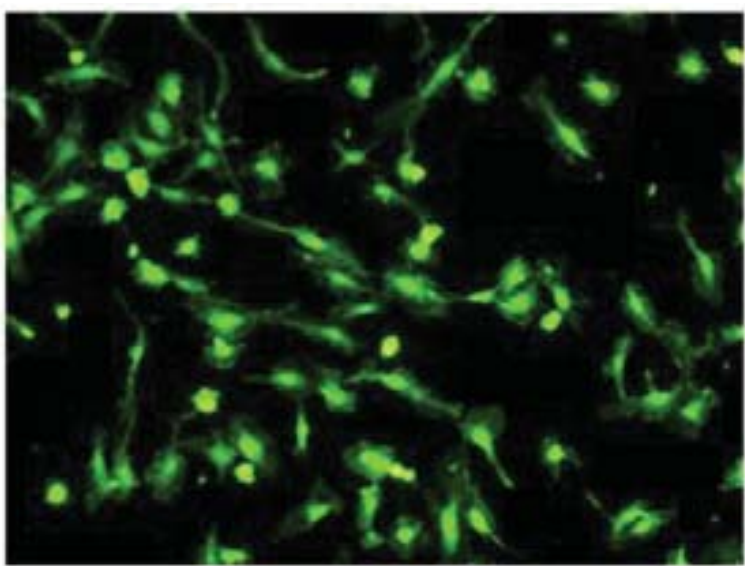

$200 \mu \mathrm{m}$

Titanium, c-RGD

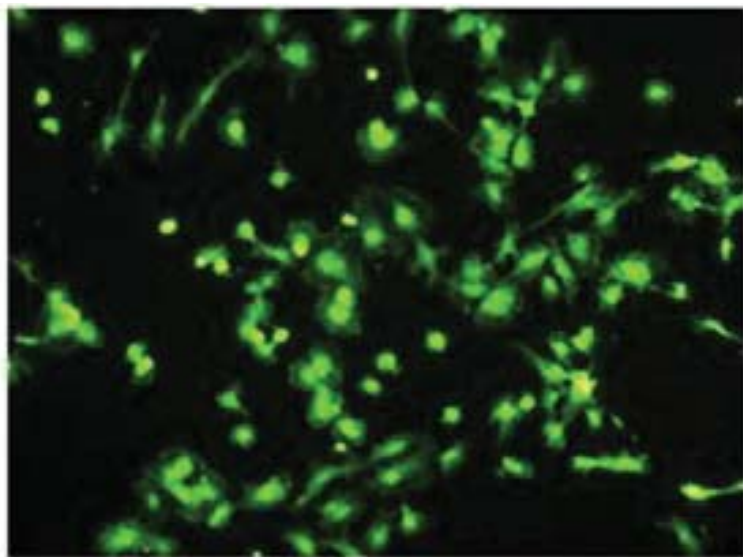

$200 \mu \mathrm{m}$

Fig. 3. ECs on pre-treated surfaces after $24 \mathrm{~h}$ of incubation

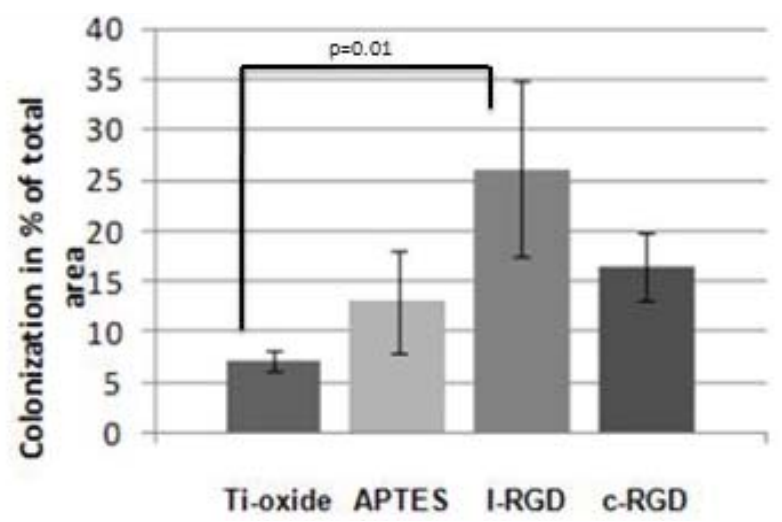

a) After 24 hours

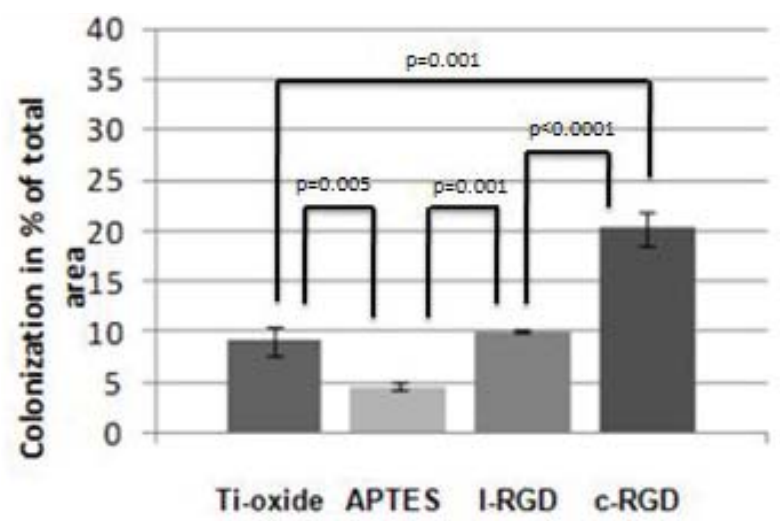

a) After 3 days

Fig. 4. Percentage of EC-colonisation on pre-treated titanium surfaces after (a) $24 \mathrm{~h}$ and (b) 3 d. Statistically significant differences are given. 


\section{Titanium, oxidised}

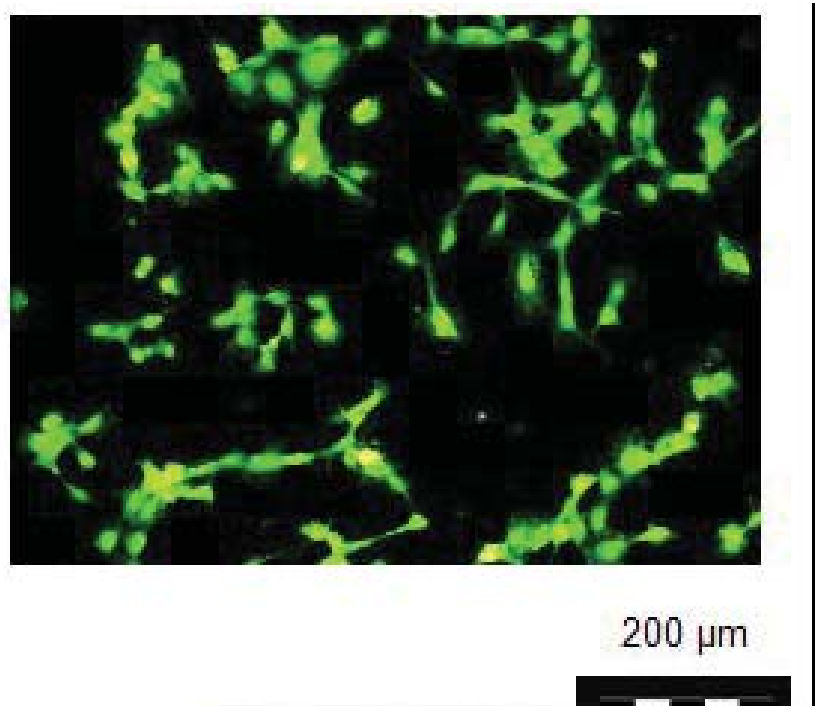

Titanium, 1-RGD

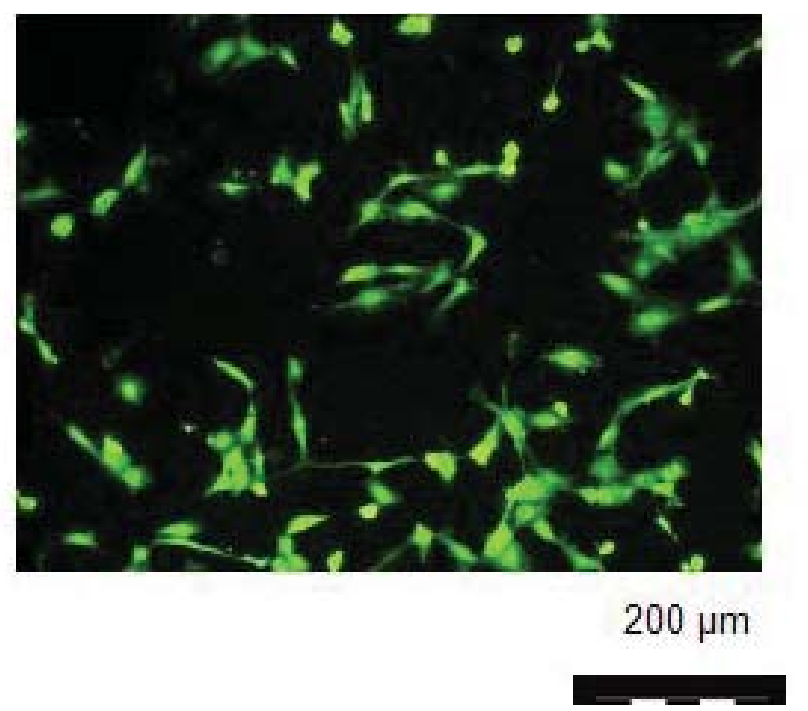

Fig. 5. ECs on pre-treated surfaces after $3 \mathrm{~d}$ of incubation.
Titanium, silanised (APTES)

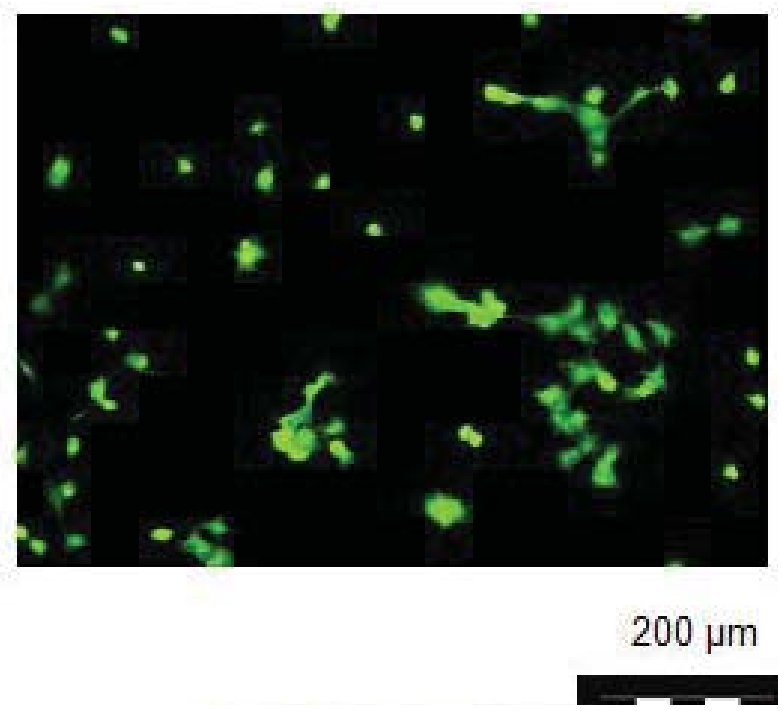

Titanium, c-RGD

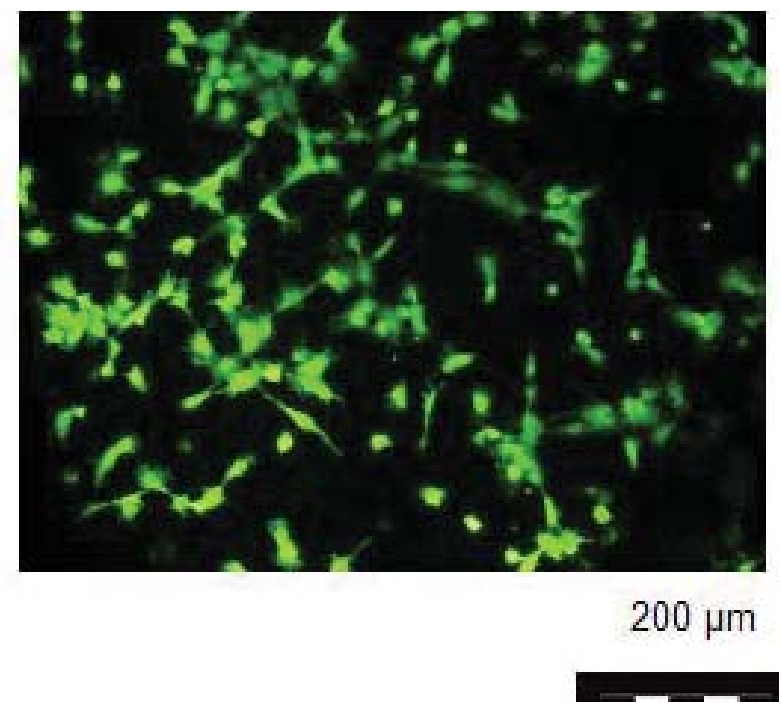

significant difference could be found between untreated and 1-RGD surfaces $(p=0.54)$. The comparison between 1-RGD and c-RGD surfaces showed a significant difference $(p=0.023)$ in favour of the c-RGD coated titanium (Fig. $6 b)$.

\section{Discussion}

The RGD-sequence (Arg-Gly-Asp) is a central element of the integrin-mediated signal transmitting cascade of endothelial cells (outside-in signalling). It has been demonstrated that the RGD-peptide motif alone is sufficient to stimulate cell activity. Accordingly, an improvement of cell adhesion and further cell activity on surfaces of RGDcoated biomaterials has been reported (Rezania and Healy, 1999, Germanier et al., 2006). For RGD-coated synthetic membranes, an enhanced viability of endothelial cells, in accordance with our results, was already proven (Choi et al., 2008; De Mel et al., 2009; Huang et al., 2010). Also, for RGD-coated dental implants, an improved osseointegration has been shown (Schliephake et al., 2002; Schliephake et al., 2005).

RGD-peptides can be manufactured synthetically; there is no potential for the transmission of diseases. Additionally, the peptides are heat-resistant and can be sterilised without damage (Hersel et al., 2003). Therefore, their use might be beneficial in later clinical settings. However, examination of RGD-stability after immobilisation in implant handling needs further in vitro and in vivo examination.

The RGD-peptide can be synthesised in a linear and in a cyclic form. Between the two forms, functional differences in the interaction between cells and surfaces are described (Verrier et al., 2002). It is of much interest to examine the conformation of the RGD-peptide, which once immobilised to titanium surfaces, will be able to improve biointegration of an implant by stimulation of ECs. The cyclic peptide seems to enhance the binding 


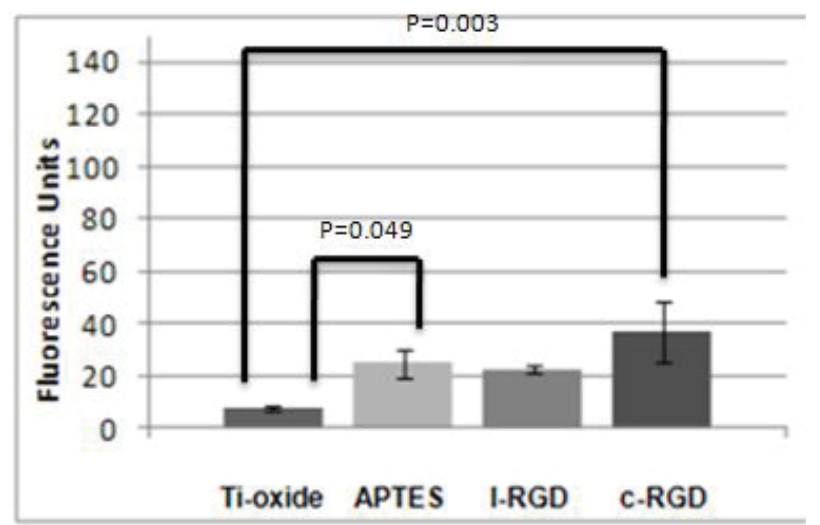

a) 24 hours

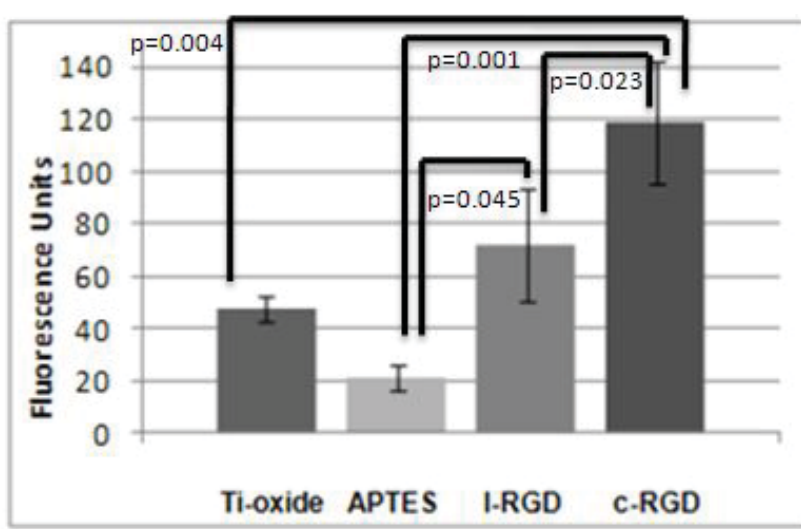

b) 3 days

Fig. 6. Intensity of fluorescence/proliferation activity of ECs on pretreated titanium surfaces after (a) 24 h and (b) 3 d. Proliferative activity was calculated as fluorescence changes based on blank controls. Statistical significant differences are given.

capacity of osteogenic cells on surfaces (Delforge et al., 1998; Hsiong et al., 2008; Zhu et al., 2009). A difference in EC cell coverage and proliferation on titanium surfaces by means of the structure of RGD peptides, which could be shown in our study, has not been investigated.

The analysis of EC coverage consisted of a quantitative interpretation of fluorescent microscopic photographs. Thereby, a visual assessment of EC characteristics (cell count and cell shape) on the different surfaces was conducted. For proliferation, the alamarBlue ${ }^{\circledR}$ assay was used. The resultant change of fluorescence activity can be used as marker of proliferation and cell activity (De Mel et al., 2009).

ECs seem to respond to RGD modified surfaces with an increased cell coverage and proliferation. This activity might be contributed the expression of the RGD binding integrin receptor $\alpha \mathrm{V} \beta 3$ on EC surfaces (Tagada et al., 2007). After 24 h, EC coverage and proliferation was facilitated on silanised and RGD modified surfaces. After $3 \mathrm{~d}$, the strongest cell coverage and proliferation was seen on the surfaces coated with cyclic RGD peptide. For EC coverage on oxidised titanium surfaces after $24 \mathrm{~h}, 1-\mathrm{RGD}$ was superior to c-RGD but not after $3 \mathrm{~d}$. This suggests that non-covalent attachment of l-RGD is more efficient but less stable compared to c-RGD. However, this positive effect of l-RGD was not observed for EC proliferation.

The prolonged and more consistent effect of c-RGD may be due to one of the major advantages of small cyclo-peptides, which is their resistance to proteolysis (Bogdanowich-Knipp et al., 1999; Haubner et al., 1996). The stronger effect of cyclic RGD after $3 \mathrm{~d}$ can be further explained by its potentially higher activity due to its specific binding capacity to the integrins $\alpha \mathrm{V} \beta 3$ and $\alpha \mathrm{V} \beta 5$ (Dechantsreiter et al., 1999) and its fibronectin-like sterical conformation (Leahy et al., 1996). The ability of cyclo-peptides to bind with higher affinities, as linear peptides to integrin receptors, have been described to be their second major advantage (Bogdanowich-Knipp et al., 1999; Haubner et al., 1996).

\section{Conclusion}

For the 1-RGD and c-RGD titanium surface coatings, a positive influence on cell coverage and proliferation of ECs was demonstrated. After 3 d, c-RGD-modified surfaces showed a significantly increased influence on EC coverage and proliferation compared to the l-RGD modified surfaces and compared to the untreated and silanised samples. For EC surface coverage and proliferation, the superiority of c-RGD- compared to 1-RGD-coated titanium could be shown. A coating of titanium surfaces with c-RGD peptide may help to direct longer-lasting selective tissue responses. The positive results of c-RGD-coatings on EC stimulation needs to be confirmed in follow-up in vivo experiments.

\section{Acknowledgements}

We thank Dr. E. Stender, Institute for Dental Material Sciences and Technology, University Medical Centre of the Johannes Gutenberg-University Mainz, for help with SEM experiments.

\section{References}

Ahmed SA, Gogal RM, Walsh JE (1994) A new rapid and simple non-radioactive assay to monitor and determine the proliferation of lymphocytes: An alternative to [3H] thymidine incorporation assay. J Immunol Methods 170: 211-224.

Al-Nawas B, Götz H (2003) Three-dimensional topographic and metrologic evaluation of dental implants by confocal laser scanning microscopy. Clin Implant Dent Relat Res 5: 176-183.

An N, Schedle A, Wieland M, Andrukhov O, Matejka M, Rausch-Fan X (2009) Proliferation, behavior, and cytokine gene expression of human umbilical vascular endothelial cells in response to different titanium surfaces. J Biomed Mater Res A 93: 364-372. 
Balaji SM (2008) Tobacco smoking and surgical healing of oral tissues: A review. Indian J Dent Res 19: 344-348.

Bhadriraju K, Hansen LK (2000) Hepatocyte adhesion, growth and differentiated function on RGD-containing proteins. Biomaterials 21: 267-272.

Bogdanowich-Knipp SJ, Chakrabarti S, Williams TD, Dillman RK, Siahaan TJ (1999) Solution stability of linear vs. cyclic RGD peptides. J Pept Res 53: 530-541.

Bouletreau PJ, Warren SM, Spector JA, Peled ZM, Gerrets RP, Greenwald JA, Longaker MT (2002) Hypoxia and VEGF up-Regulate BMP-2 mRNA and protein expression in microvascular endothelial cells: Implications for fracture healing. Plast Reconstr Surg 109: 2384-2397.

Burkhardt R, Kettner G, Bohm W, Schmidmeier M, Schlag R, Frisch B, Mallmann B, Eisenmenger W, Gilg T (1987) Changes in trabecular bone, hematopoiesis and bone marrow vessels in aplastic anemia, primary osteoporosis, and old age: A comparative histomorphometric study. Bone 8: $157-164$.

Carano RA, Filvaroff EH (2003) Angiogenesis and bone repair. Drug Discov Today 8: 980-989.

Choi WS, Bae JW, Lim HR, Joung YK, Park JC, Kwon IK, Park KD (2008) RGD peptide-immobilized electrospun matrix of polyurethane for enhanced endothelial cell affinity. Biomed Mater 3: 44104.

Davies MG, Hagen PO (1993) The vascular endothelium. A new horizon. Ann Surg 218: 593-609.

De Mel A, Punshon G, Ramesh B, Sarkar S, Darbyshire A, Hamilton G, Seifalian AM (2009) In situ endothelialization potential of a biofunctionalised nanocomposite biomaterial-based small diameter bypass graft. Biomed Mater Eng 19: 317-331.

Dechantsreiter MA, Planker E, Matha B, Lohof E, Holzemann G, Jonczyk A, Goodman SL, Kessler H (1999) $\mathrm{N}$-methylated cyclic RGD peptides as highly active and selective $\alpha_{\mathrm{v}} \beta_{3}$ integrin antagonists. J Med Chem 42: 3033 3040 .

Delforge D, Gillon B, Art M, Dewelle J, Raes M, Remacle J (1998) Design of a synthetic adhesion protein by grafting RGD tailed cyclic peptides on bovine serum albumin. Lett Pept Sci 5: 87-91.

Ferris DM, Moodie GD, Dimond PM, Gioranni CWD, Ehrlich MG, Valentini RF (1999) RGD-coated titanium implants stimulate increased bone formation in vivo. Biomaterials 20: 2323-2331.

Fine E, Zhang L, Fenniri H, Webster TJ (2009) Enhanced endothelial cell functions on rosette nanotubecoated titanium vascular stents. Int J Nanomedicine 4: 91-97.

Germanier Y, Tosatti S, Broggini N, Textor M, Buser D (2006) Enhanced bone apposition around biofunctionalized sandblasted and acid-etched titanium implant surfaces. A histomorphometric study in miniature pigs. Clin Oral Implants Res 17: 251-257.

Glowacki J (1998) Angiogenesis in fracture repair. Clin Orthop Relat Res 355 Suppl: S82-89.

Haubner R, Gratias R, Diefenbach B, Goodman SL, Jonczyk A, Kessler H (1996) Structural and functional aspect of RGD-containing cyclic pentapeptides as highly potent and selective integrin AVB3 antagonist. J Am Chem Soc 118: 7461-7472.

Hausman MR, Schaffler MB, Majeska RJ (2001) Prevention of fracture healing in rats by an inhibitor of angiogenesis. Bone 29: 560-564.

Hersel U, Dahmen C, Kessler H (2003) RGD modified polymers: Biomaterials for stimulated cell adhesion and beyond. Biomaterials 24: 4385-4415.

Hirano Y, Okuno M, Hayashi T, Goto K, Nakajima A (1993) Cell-attachment activities of surface immobilized oligopeptides RGD, RGDS, RGDV, RGDT, and YIGGS toward five cell lines. J Biomater Sci Polym Ed 4: 235-243.

Holland NB, Qiu Y, Ruegsegger M, Marchant RE (1998) Biomimetic engineering of non-adhesive glycocalyx-like surfaces using oligosaccharide surfactant polymers. Nature 392: 799-801.

Hsiong SX, Boontheekul T, Huebsch N, Mooney DJ (2008) Cyclic arginine-glycine-aspartate peptides enhance three-dimensional stem cell osteogenic differentiation. Tissue Eng A 15: 263-272.

Huang X, Zauscher S, Klitzman B, Truskey GA, Reichert WM, Kenan DJ, Grinstaff MW (2010) Peptide interfacial biomaterials improve endothelial cell adhesion and spreading on synthetic polyglycolic acid materials. Ann Biomed Eng 38: 1965-1976

Huang YC, Kaigler D, Rice KG, Krebsbach PH, Mooney DJ (2005) Combined angiogenic and osteogenic factor delivery enhances bone marrow stromal cell-driven bone regeneration. J Bone Miner Res 20: 848-857.

Huynh-Ba G, Friedberg JR, Vogiatzi D, Ioannidou E (2008) Implant failure predictors in the posterior maxilla: A retrospective study of 273 consecutive implants. J Periodontol 79: 2256-2261.

James NL, Schindhelm K, Slowiaczek P, Milthorpe BK, Dudman NP, Johnson G, Steele JG (1990) Endothelial cell seeding of small diameter vascular grafts. Artif Organs 14: 355-360.

Javed F, Romanos GE (2009) Impact of diabetes mellitus and glycemic control on the osseointegration of dental implants: A systematic literature review. J Periodontol 80: 1719-1730.

Kanczler JM, Oreffo RO (2008) Osteogenesis and angiogenesis: The potential for engineering bone. Eur Cell Mater 15: 100-114.

Kim J, Hong SY, Park HS, Kim DS, Lee W (2005) Structure and function of RGD peptides derived from disintegrin proteins. Mol Cells 19: 205-211.

Kostidis S, Stavrakoudis A, Biris N, Tsoukatos D, Sakarellos C, Tsikaris V (2004) The relative orientation of the Arg and Asp side chains defined by a pseudodihedral angle as a key criterion for evaluating the structure-activity relationship of RGD peptides. J Pept Sci 10: 494-509.

Kroese-Deutman HC, Van den Dolder J, Spauwen PHM, Jansen JA (2005) Influence of RGD-loaded titanium implants on bone formation in vivo. Tiss Eng 11: 18671875.

Leahy DJ, Aukhil I, Erickson HP (1996) 2.0 A crystal structure of a four-domain segment of human fibronectin encompassing the RGD loop and synergy region. Cell 84: 155-164. 
Lin HB, Garcia-Echeverria C, Asakura S, Sun W, Mosher DF, Cooper SL (1992) Endothelial cell adhesion on polyurethanes containing covalently attached RGDpeptides. Biomaterials 13: 905-914.

Lin HB, Sun W, Mosher DF, Garciaecheverria C, Schaufelberger K, Lelkes PI, Cooper SL (1994) Synthesis, surface, and cell-adhesion properties of polyurethanes containing covalently grafted RGD-peptides. J Biomed Mater Res 28: 329-342.

Lin YS, Wang SS, Chung TW, Wang YH, Chiou SH, Hsu JJ, Chou NK, Hsieh KH, Chu SH (2001) Growth of endothelial cells on different concentrations of Gly-ArgGly-Asp photochemically grafted in polyethylene glycol modified polyurethane. Artif Organs 25: 617-621.

Linsen SS, Martini M, Stark H (2009) Long-term results of endosteal implants following radical oral cancer surgery with and without adjuvant radiation therapy. Clin Implant Dent Relat Res, in press.

Massia SP, Stark J (2001) Immobilized RGD peptides on surface-grafted dextran promote biospecific cell attachment. J Biomed Mater Res 56: 390-399.

Matsuura T, Hosokawa R, Okamoto K, Kimoto T, Akagawa Y (2000) Diverse Mechanisms of osteoblast spreading on hydroxyapatite and titanium. Biomaterials 21: 1121-1127.

Mellado-Valero A, Ferrer-Garcia JC, Labaig-Rueda C, Calvo-Catala J (2009) Implant treatment in patients with osteoporosis. Med Oral Patol Oral Cir Bucal 15: 52-57.

Pallu S, Fricain JC, Bareille R, Bourget C, Dard M, Sewing A, Amedee J (2009) Cyclo-DFKRG peptide modulates in vitro and in vivo behavior of human osteoprogenitor cells on titanium alloys. Acta Biomater 5: 3581-3592.

Rezania A, Healy KE (1999) Biomimetic peptide surfaces that regulate adhesion, spreading, cytoskeletal organization, and mineralization of the matrix deposited by osteoblast-like cells. Biotechnol Prog 15: 19-32.

Schliephake H, Scharnweber D, Dard M, Rossler S, Sewing A, Meyer J, Hoogestraat D (2002) Effect of RGD peptide coating of titanium implants on periimplant bone formation in the alveolar crest. An experimental pilot study in dogs. Clin Oral Implants Res 13: 312-319.

Schliephake H, Scharnweber D, Dard M, Sewing A, Aref A, Roessler S (2005) Functionalization of dental implant surfaces using adhesion molecules. J Biomed Mater Res B Appl Biomater 73: 88-96.

Secchi AG, Grigoriou V, Shapiro IM, Cavalcanti-Adam EA, Composto RJ, Ducheyne P, Adams CS (2007) RGDS peptides immobilized on titanium alloy stimulate bone cell attachment, differentiation and confer resistance to apoptosis. J Biomed Mater Res A 83: 577-584.

Tagada Y, Ye X, Simon S (2007) The integrins. Genom Biol 8: 215.

Verrier S, Pallu S, Bareille R, Jonczyk A, Meyer J, Dard M, Amedee J (2002) Function of linear and cyclic RGD-containing peptides in osteoprogenitor cells adhesion process. Biomaterials 23: 585-596.

Wacker BK, Alford SK, Scott EA, Thakur MD, Longmore GD, Elbert DL (2008) Endothelial cell migration on RGD-peptide-containing PEG hydrogels in the presence of shingosine 1-Phosphate. Biophys J 94: 273-285.

Wang DS, Miura M, Demura H, Sato K (1997) Anabolic effects of 1,25-dihydroxyvitamin D3 on osteoblasts are enhanced by vascular endothelial growth factor produced by osteoblasts and by growth factors produced by endothelial cells. Endocrinology 138: 2953-2962.

Wu KK, Frasier-Scott K, Hatzakis H (1988) Endothelial cell Function in hemostasis and thrombosis. Adv Exp Med Biol 242: 127-133.

Xiao Y, Truskey GA (1996) Effect of receptor-ligand affinity on the strength of endothelial cell adhesion. Biophys J 71: 2869-2884.

Zhu J, Tang C, Kottke-Marchant K, Marchant RE (2009) Design and synthesis of biomimetic hydrogel scaffolds with controlled organization of cyclic RGD peptides. Bioconjug Chem 20: 333-339.

\section{Discussion with Reviewers}

Reviewer I: Have the authors any idea as to the stability of their coatings i.e., can they be handled without damaging etc.?"

Authors: This important issue has not been examined in our study. This topic is under evaluation and will be part of our next paper.

Reviewer II: Normalisation of cell proliferation assay - the method used (normalised to control surface) is a bit vague. For instance, a $279 \%$ increase may sound like a lot but without any indication of the cell number being normalised to, this is misleading. What was the actual cell number?

Authors: Generally, nearly $100 \%$ of seeded cells adhere after $24 \mathrm{~h}$. We found in our experiments no evidence for lowered adhesion or increased dead cell counts. Therefore, we assumed to measure proliferation and adhesion from at least 50,000 cells after $24 \mathrm{~h}$, which should be sufficient for a reliable calculation. 